\title{
Interleukin-17 expression in murine pressure ulcer tissues
}

\author{
WEI CUI ${ }^{1}$, LEI-FANG YANG ${ }^{1}$, WEN-HONG WEI ${ }^{1}$, YA-QIN ZHU ${ }^{1}$, XIAO WU $^{2}$, \\ PEI-XIA MU ${ }^{1}$ and SHU-PING GUO ${ }^{3}$ \\ Departments of ${ }^{1}$ Special Medical Service, ${ }^{2}$ Cardiology and ${ }^{3}$ Surgical Oncology, \\ The Central Hospital of Xinxiang, Xinxiang, Henan 453600, P.R. China
}

Received November 11, 2012; Accepted January 9, 2013

DOI: 10.3892/etm.2013.912

\begin{abstract}
To explore the process of pressure ulcer formation, interleukin (IL)-17 expression levels were observed in a mouse model of pressure ulcers. Twenty mice were divided into experimental and control groups (10 mice per group). A mouse model of pressure ulcers was established by inducing ischemiareperfusion injury on local tissue in the experimental group. Pressure ulcer tissues in the experimental group and normal mouse tissue in the control group were stained using hematoxylin and eosin (H\&E) and observed using light microscopy. The protein and mRNA expression levels of IL-17, in mouse pressure ulcer tissues from the experimental group and in the normal tissue from the control group, were determined using real-time PCR and western blot analysis, respectively. The mRNA and protein expression levels of IL-17 were compared between the two groups. H\&E staining indicated that striated muscle was arranged orderly and cellular structure was intact in the control group, whilst inflammatory cell infiltration was observed in the muscle tissue of the experimental group. The expression levels of IL-17 mRNA were $0.307 \pm 0.058 \mathrm{ng}$ in the experimental group and $0.112 \pm 0.042 \mathrm{ng}$ in the control group $(\mathrm{P}<0.05)$. The expression levels of the IL-17 protein were $0.434 \pm 0.097 \mathrm{ng}$ in the experimental group and $0.181 \pm 0.040 \mathrm{ng}$ in the control group $(\mathrm{P}<0.05)$. IL-17 expression levels were increased in pressure ulcers, which suggests that IL-17 may be associated with pressure ulcers.
\end{abstract}

\section{Introduction}

Pressure ulcers, also know as bedsores, occur when long-term pressure to local tissue causes disruption to blood flow and tissue nutritional deficiency, which leads to skin ulceration and necrosis (1). Pressure ulcers have always been a difficult problem in clinical care and are one of the most common complications in bedridden patients. Patients with severe pressure ulcers may develop septicemia and this often results in

Correspondence to: Miss Lei-Fang Yang, Department of Special Medical Service, The Central Hospital of Xinxiang, 56 Jinsui Avenue, Xinxiang, Henan 453000, P.R. China

E-mail: zf.23380681@163.com

Key words: pressure ulcer, animal model, interleukin-17 mortality. Therefore, it is crucial to discover methods to prevent and treat pressure ulcers effectively. Interleukin (IL)-17 is a cytokine which is associated with inflammatory reactions (2). This study aimed to investigate the role of IL-17 in pressure ulcers to determine how they may be related. A mouse model of pressure ulcers was established and IL-17 expression was observed in an attempt to find an effective method to prevent and treat pressure ulcers.

\section{Materials and methods}

Animals. All methods in this study were approved by the Ethics Committee of the First Affiliated Hospital of Liaoning Medical University. Twenty 8-week-old BALB/c mice of either gender and weighing 25-28 g were purchased from the Experimental Animal Center, Dalian Medical University [License number: SCXK (Liaoning) 2008-0002].

Apparatus and reagents. A TC-512 gene amplification instrument, a UV Analyzer, a GeneGenius automated gel imaging system, a BIO-RAD semi-dry transfer instrument, an IBox 600 in vivo imaging system, an RNA PCR kit (AMV) Ver 3.0 and Sepharose ${ }^{\circledR}$ were purchased from Takara Bio, Inc. (Dalian, China). IL-17 and $\beta$-actin primers were synthesized by Shanghai Sangon Biological Engineering Technology and Service Co., Ltd. (Shanghai, China). IL-17 (H-132) rabbit polyclonal antibody was purchased from Santa Cruz Biotechnology, Inc. (Santa Cruz, CA, USA). Goat antirabbit IgG was purchased from Beijing Zhongshan Jinqiao Biotechnology Co., Ltd. (Beijing, China). Hematoxylin, 4\% formaldehyde and eosin were purchased from Chemical Reagent Factory (Shanghai, China).

Grouping. Twenty mice were divided into experimental and control groups (10 mice per group). Ischemia-reperfusion injury was induced on local tissue in the experimental group.

Preparation of pressure ulcer mouse model. A mouse model of pressure ulcer was produced in accordance with previously described methods $(3,4)$. Mice were fasted for $12 \mathrm{~h}$ prior to surgery, anesthetized by intraperitoneal injection of pentobarbital sodium $(0.5 \mathrm{mg} / 10 \mathrm{~g})$ and skin preparation was performed. A sterile metal magnetic disk (5x12 mm, $2.4 \mathrm{~g}, 1000$ Gauss) was placed on the skin at the hip joint and another metal magnetic disk (5x12 mm, $2.4 \mathrm{~g}, 1000$ Gauss) was placed at the groin to 
produce a magnetic force of $50 \mathrm{mmHg}(1 \mathrm{mmHg}, 0.133 \mathrm{kPa}$, $40.7 \mathrm{~g}$ ). In the experimental group, $2 \mathrm{~h}$ of ischemia and $0.5 \mathrm{~h}$ of reperfusion were employed in a cycle; five cycles were performed to induce a pressure ulcer. To ensure the balance of water and electrolytes, $0.5 \mathrm{ml}$ glucose-saline solution was administered via the caudal vein every $2.5 \mathrm{~h}(5)$. When the experiment had ended, the mice were sacrificed by cervical dislocation.

Criteria for successful models. The gross appearance of mouse skin was red with breakages, ulceration and necrosis. Pathological changes, including muscle fiber atrophy, widened interstitial spaces, inflammatory cell infiltration and unclear transverse striation, were observed in mouse pressure ulcers under a light microscope.

Hematoxylin and eosin $(H \& E)$ stain for mouse muscle tissue in pressure ulcer. Muscle tissue in the pressure ulcer was fixed with $4 \%$ paraformaldehyde for $12 \mathrm{~h}$, dehydrated with gradient alcohol and washed twice with xylene for $0.5-1 \mathrm{~h}$. Once it had become transparent, the muscle tissue was embedded in paraffin and sliced into sections.

Following deparaffinization with xylene, the sections were dehydrated with down-gradient alcohol, stained with hematoxylin for 5-10 min and washed with distilled water for $10 \mathrm{~min}$. Several seconds after the addition of $1 \%$ hydrochloric acid alcohol, the sections were washed with tap water for 30-40 min, dehydrated with up-gradient alcohol, rendered transparent by immersion in xylene for $10 \mathrm{~min}$ and mounted with neutral gum for observation under a light microscope.

IL-17 mRNA expression in mouse pressure ulcer tissue determined using real-time (RT)-PCR. Muscle tissue ( $\sim 50 \mathrm{mg})$ was placed in a sterile Eppendorf (EP) tube and the total RNA was extracted according to the manufacturer's instructions. The reverse transcription of cDNA was performed according to the manufacturer's instructions for RNA PCR kit (AMV; Takara, Dalian, China) Ver 3.0. Reverse transcription was performed in a $10 \mu \mathrm{l}$ volume containing $1.0 \mu \mathrm{l} 10 \mathrm{X}$ RT buffer, $2.0 \mu \mathrm{l} \mathrm{MgCl}_{2}, 3.75 \mu \mathrm{l}$ RNA-free $\mathrm{dH}_{2} \mathrm{O}, 1.0 \mu \mathrm{l}$ dNTP mixture, $0.25 \mu 1$ RNase Inhibitor, $0.5 \mu 1$ AMV Reverse Transcriptase, $0.5 \mu \mathrm{l}$ oligo(dT) adaptor primer and $1 \mu \mathrm{l}$ total RNA. The reaction conditions were as follows: $30^{\circ} \mathrm{C}$ for $10 \mathrm{~min}, 42^{\circ} \mathrm{C}$ for $30 \mathrm{~min}$ and $99^{\circ} \mathrm{C}$ for $5 \mathrm{~min}$. Samples were stored at $-20^{\circ} \mathrm{C}$ for future use. In PCR, the primers used for IL-17 (6) were P1, 5'-AGATCTGGACGCGCAAACATGAG-3' and P2, 5'-GGGTCGTCGACGGGTCTCTGTTTAG-3' with an amplified fragment of $516 \mathrm{bp}$. The primers used for $\beta$-actin (7) were P1, 5'-AGAGGGAAATCGTGCGTGAC-3' and P2, 5'-CAATAGTGATGACCTGGCCGT-3' with an amplified fragment of $138 \mathrm{bp}$. PCR was performed in a volume of $20 \mu \mathrm{l}$ containing 2.0 $\mu \mathrm{l}$ 10X PCR buffer $\left(\mathrm{Mg}^{2+}\right.$-free), $1.0 \mu \mathrm{l}$ of $25 \mathrm{mmol} / \mathrm{l} \mathrm{MgCl}{ }_{2}, 1 \mu \mathrm{l}$ of $2 \mathrm{mmol} / \mathrm{ldNTP}, 0.5 \mu \mathrm{l}$ up- and downstream IL-17 primer, $0.5 \mu \mathrm{l}$ up- and downstream $\beta$-actin primer, $2 \mu \mathrm{l}$ cDNA template, $0.2 \mu 1$ Ex Taq HS and $11.8 \mu 1$ ultrapure water. Reaction conditions were as follows: $94^{\circ} \mathrm{C}$ for $5 \mathrm{~min}, 94^{\circ} \mathrm{C}$ for $30 \mathrm{sec}, 51^{\circ} \mathrm{C}$ for $45 \mathrm{sec}$ and $72^{\circ} \mathrm{C}$ for $30 \mathrm{sec}$ for 35 cycles. Finally elongation was carried out at $72^{\circ} \mathrm{C}$ for $5 \mathrm{~min}$. PCR products underwent $1.5 \%$ agarose gel electrophoresis. Images were obtained using a UV Analyzer. Grayscale values were obtained and analyzed with GeneGenius and GeneTool analysis systems.
Table I. IL-17 mRNA expression in mouse pressure ulcer muscle tissue (mean $\pm \mathrm{SD})$.

\begin{tabular}{lcccc}
\hline Group & Mice (n) & IL-17 mRNA & t & P-value \\
\hline Experimental & 10 & $0.307 \pm 0.058$ & 8.595 & 0.000 \\
Control & 10 & $0.112 \pm 0.042$ & & \\
\hline
\end{tabular}

IL-17, interleukin-17.

IL-17 protein expression in mouse pressure ulcer tissue determined using western blot analysis. Muscle tissue $(\sim 50 \mathrm{mg})$ was placed in a sterile EP tube and cell disruption was performed. The protein was extracted and its concentration was determined using the bicinchoninic acid (BCA) method. Samples were prepared according to the protein concentrations and were boiled for 5 min following addition of reducing sample buffer (RSB) and Tris-buffered saline (TBS). The samples were stored at $-20^{\circ} \mathrm{C}$ for future use. Each sample $(20 \mu \mathrm{l})$ underwent SDS-PAGE and was then transferred to a membrane. The membrane was sealed with $1 \%$ bovine serum albumin (BSA) for $1 \mathrm{~h}$, followed by the addition of anti-IL-17 polyclonal antibodies for overnight incubation. The membrane was washed with TBS for $5 \mathrm{~min}$ three times. Horseradish peroxidase-conjugated secondary antibody was added for a 1-h incubation. The membrane was washed with TBS for 5 min three times, followed by enhanced chemiluminescence (ECL) coloration in the dark. Grayscale values were analyzed using an IBox 600 in vivo imaging system (Tianmei Scientific Instrument Co., Ltd., Shanghai, China).

Statistical analysis. Statistical analysis was performed using SPSS software. The data are expressed as mean \pm SD. An independent sample t-test was used for comparisons between the two groups. $\mathrm{P}<0.05$ was considered to indicate a statistically significant difference.

\section{Results}

Macroscopic observation. In the experimental group, mouse skin integrity was damaged and exhibited exudation, erosion and necrosis. In the control group, no marked changes were observed in mouse skin.

Changes in mouse pressure ulcer muscle tissue viewed under a light microscope. In the experimental group, degenerative tearing, disappearance of transverse striation, myolysis and inflammatory cell infiltration were observed in skeletal muscle. Cell infiltration included neutrophilic granulocytes with pink cytoplasm and a blue lobulated nucleus and lymphocytes with less cytoplasm and a large nucleus (Fig. 1A). In the control group, striated muscle was arranged in order and cellular structure was intact (Fig. 1B).

IL-17 mRNA expression in mouse pressure ulcer tissue determined using RT-PCR. RT-PCR showed the specific band for $516 \mathrm{bp}$ in the two groups. Compared with the control group, IL-17 mRNA expression was significantly upregulated in the experimental group ( $\mathrm{P}<0.01$; Table I and Fig. 2). 
Table II. IL-17 protein expression in mouse pressure ulcer muscle tissue (mean $\pm \mathrm{SD}$ ).

\begin{tabular}{lcccc}
\hline Group & Mice (n) & IL-17 & t & P-value \\
\hline Experimental & 10 & $0.434 \pm 0.097$ & 7.608 & 0.000 \\
Control & 10 & $0.181 \pm 0.040$ & & \\
\hline
\end{tabular}

IL-17, interleukin-17.

A

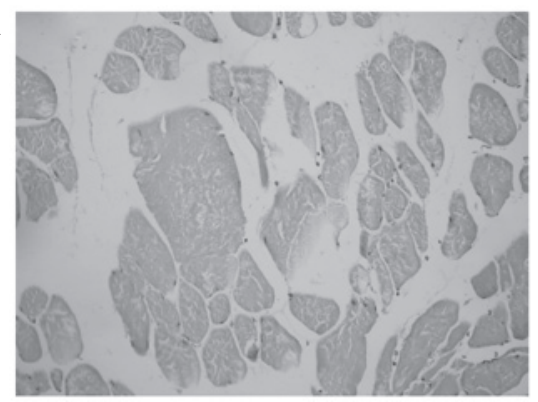

B

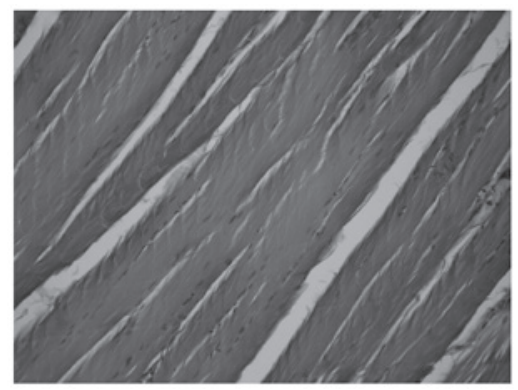

Figure 1. (A) H\&E staining for mouse pressure ulcer muscle tissue in the experimental group. (B) H\&E staining for normal muscle tissue in the control group. Magnification, x400. H\&E, hematoxylin and eosin.

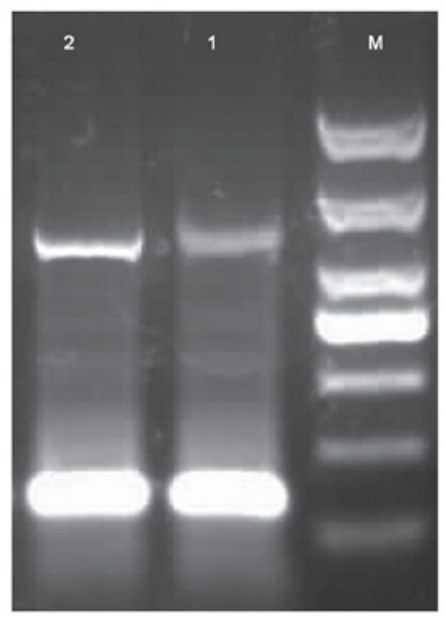

Figure 2. Interleukin-17 mRNA expression in mouse pressure ulcer and normal tissue. Lane M, DL1000; lane 1, control group; lane 2, experimental group.

IL-17 protein expression in mouse pressure ulcer tissue determined using western blot analysis. Western blot analysis showed the specific band for $15 \mathrm{kDa}$ in the two groups. Compared with the control group, IL-17 protein expression

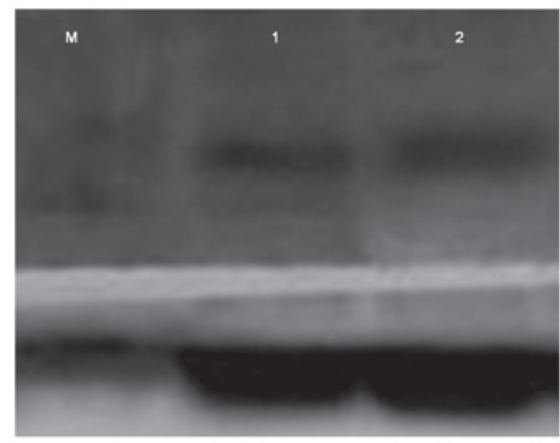

Figure 3. Interleukin-17 protein expression in pressure ulcer muscle tissue Lane M, DL1000; lane 1, control group; lane 2, experimental group.

was significantly upregulated in the experimental group $(\mathrm{P}<0.01$; Table II and Fig. 3).

\section{Discussion}

Long-term pressure on soft tissue causes disruption to blood circulation and vascular endothelial cell injury. Continuous platelet agglomeration leads to the occurrence of microcirculation thrombosis, which aggravates local tissue ischemia (8). Long-term tissue ischemia and hypoxia may induce metabolic disorders in tissue and cells and changes in plasma colloid osmotic pressure, which leads to cellular edema and perhaps even cell rupture (9). Damage to the tissue produces selfdefensive and protective reactions to recover normal function. However, metabolic compensation is not able to maintain normal function for long, due to long-term demands on the local tissue and when metabolic disruption results in the production of oxygen free radicals and their derivatives, tissue damage is aggravated (10). This results in severe tissue damage which causes infection and inflammation to occur repeatedly. In this study, pressure ulcer mouse models were established and IL-17 expression was observed in an attempt to find an effective method to prevent and treat pressure ulcers.

H\&E staining results revealed neutrophil and lymphocyte infiltration of mouse muscle tissue in the experimental group and well-arranged striated muscle and intact cells in the control group. IL-17 (IL-17A) is mainly secreted by Th17 cells of the $\mathrm{CD}^{+} \mathrm{T}$ lymphocyte subset. Th17 cells exert their biological effects via the secretion of IL-17A, IL-17F, IL-6, IL-22 and TNF- $\alpha$, which signals neutrophils to move towards the site of inflammation and play an infection-fighting role in the early stage of the immune response (11-13). The results of this study indicated that the expression of IL-17 mRNA and protein occurred in the two groups, however these expression levels were significantly increased in the experimental group compared with the control group $(\mathrm{P}<0.01)$. This is suggestive of overexpression of IL-17 in mouse pressure ulcer muscle tissue, which is associated with the occurrence and development of inflammatory lesions. IL-17 stimulates the secretion of IL-6, TNF- $\alpha$, granulocyte macrophage colony-stimulating factor (GM-CSF), IL-8, IL-6, IL-1 $\beta$ and G-CSF, which allows neutrophils, polymorphonuclear cells, $\mathrm{T}$ cells and macrophages to move to the inflammation site and carry out an immune function. In this study, H\&E staining results indicated that neutrophil and lymphocyte infiltration occurs in mouse pres- 
sure ulcer muscle tissue, suggesting that IL-17 may contribute to an immune response in the development of pressure ulcers. Differentiation occurs earlier in Th17 cells than in Th1 and Th2 cells, there are fewer Th17 cells than Th1 and Th 2 cells and the effective response time is shorter in Th17 cells than in Th1 and Th2 cells, therefore it is crucial to extend the effective response time and to increase the number of Th17 cells to improve the immune effects of IL-17. When the number of Th17 cells reaches a certain threshold, Th1, Th2 and Treg cells inhibit Th17 cell differentiation. Therefore, in the persistent infection of pressure ulcers, a replacement for the role of IL-17 secreted by Th17 cells is required. Studies have shown that IFN- $\gamma$ is increased in the late phase of inflammation (14), however, whether IFN-5 plays a major role in severe pressure ulcers remains to be confirmed by future studies.

Pressure ulcer is a complex problem in clinical care. Further studies are required to discover better methods to prevent and treat pressure ulcer.

\section{References}

1. No authors listed: Pressure ulcer prevalence, cost and risk assessment: consensus development conference statement - The National Pressure Ulcer Advisory Panel. Decubitus 2: 24-28, 1989.

2. Kramer JM and Gaffen SL: Interleukin-17: a new paradigm in inflammation, autoimmunity, and therapy. J Periodontol 78: 1083-1093, 2007.

3. Stadler I, Zhang RY, Oskoui P, et al: Develoment of a simple, noninvasive, clinically relevant model of pressure ulcers in the mouse. J Invest Surg 17: 221-227, 2004.
4. Peirce SM, Skalak TC and Rodeheaver GT: Ischemia-reper-fusion injury in chronic pressure ulcer formation: a skin model in the rat. Wound Repair Regen 8: 68-76, 2000.

5. Salcido R, Fisher SB, Donofrio JC, et al: An animal model and computer controlled surface pressure delivery system for the production of pressure ulcers. J Rehabil Res Dev 32: 149-161, 1995.

6. Dong-hai Wang: IL-17 regulates T cell-mediated type I diabetes in NOD mice; long-term alcohol consumption reduces the expression of PBR and StAR in rat leydig cells. Shandong: Internal Medicine of Shandong University, 2008 (In Chinese).

7. Shuang Liu: Inhibitory effects of IL-23 gene on breast cancer in mice and its mechanism. Hebei: Hebei Medical University. Immunology, 2008 (In Chinese).

8. Witzigmann H, Ludwig S, Armann B, et al: Endothelin(A) receptor blockade reduces ischemia/reperfusion injury in pig pancreas tansplantation. Ann Surg 238: 264-274, 2003.

9. Jiang LP, Tu Q, Wang Y and Zhang E: Icshemia-reperfusion injury-induced histological changes affecting early stage pressure ulcer development in a rat model. Ostomy Wound Manage 57: 55-56, 2011.

10. Saito Y, Hasegawa M, Fujimoto M, et al: The Loss of MCP-1 attenuates cutaneous ischemia-reperfusion injury in a mouse model of pressure ulcer. J Invest Surg 128: 1838-1851, 2008.

11. Ouyang W, Kolls JK and Zheng Y: The biological funcations of Thelper 17 cell effector cy tokines in inflammation. Immunity 28: 454-467, 2008.

12. Fontao L, Bremblilla NC, Masouyé I, et al: Interleukin-17 expression in neutrophils and Th17 cells in cutaneous T-cell lymphoma associated with neutrophilic infiltrate of the skin. Br J Dermatol 166: 687-689, 2012

13. Korn T, Oukka M, Kuchroo V, et al: Th17 cell: effector T cell with inflammatory properties. Semin Immunol 19: 362-371, 2007.

14. Xu Sheng: High expression of interleukin-17 secreted by CD4<+> memory $\mathrm{T}$ cells and its mechanism. Shanghai: Immunology. Second Military Medical Univesity, 2008 (In Chinese). 